\title{
O lugar da Formação de Professores em Periódicos de Educação ${ }^{1}$
}

The Place of Teacher Education in Periodicals

Maria Auxiliadora Bueno Andrade Megid PPGE da PUC-Campinas, Unicamp

Carolina Lucenti Pereira

Pedagoga pela PUC-Campinas

\section{Resumo}

O presente trabalho analisa e mapeia 24 artigos sobre a formação inicial e/ou continuada de professores dos anos iniciais do Ensino Fundamental: nove publicados na Revista Brasileira de Educação e 15 na Zetetiké, na primeira década do século XXI. Inicialmente identificamos as temáticas, construindo um quadro de análise; depois, eixos convergentes relacionados às Políticas Públicas, Tecnologia da Informação e Comunicação, Currículo, Didática e Avaliação. O enfoque metodológico escolhido é o da análise de conteúdo. Verificamos que a concentração das publicações se dá entre os anos de 2005 a 2010 e que a maioria dos autores dos artigos está ligada às instituições públicas da região sudeste.

Palavras-chave: concepção de formação inicial de professores; formação profissional de docentes em início de carreira; formação continuada de professores.

\section{Abstract}

This study analyzes and mapping 24 articles on the initial and /or continuing teacher of the early years of elementary school: nine published in Revista Brasileira de Educação and 15 in Zetetiké in the first decade of this century. Initially identified the thematic, building a framework for analysis, then converging axes related to Public Policy, Information Technology and Communication, Curriculum, Curriculum and Assessment. The methodological approach chosen is the content analysis. We found that the concentration of publications takes place between the years 2005 to 2010 and that most of the authors of the articles are linked to public institutions in the Southeast.

Keywords: conception initial teacher education, professional training of teachers beginning their careers, continuing education of teachers.

\footnotetext{
${ }^{1}$ A pesquisa contou com o apoio do CNPQ.
} 


\section{Introdução}

O presente trabalho tem por objetivo analisar os artigos encontrados em dois periódicos de circulação nacional com foco na Educação, os quais abordam a temática da formação inicial e continuada de professores. Foram escolhidas a Revista Brasileira de Educação, da ANPEd e a Revista Zetetiké, da Faculdade de Educação da Unicamp, por se tratar de periódicos de ampla circulação nacional. No que se refere à Revista Zetetiké, indicamos um particular interesse de pesquisa na área da formação de professores de matemática. Quanto ao recorte de período para o levantamento dos artigos, escolhemos aquele compreendido entre os anos de 2001 e 2010, visto que, na busca dos enfoques atuais relacionados à Educação, interessavam-nos os trabalhos desenvolvidos e publicados mais recentemente. A escolha das revistas deveu-se em função de, nelas, encontrarmos artigos relacionados ao tema "Formação de Professores", nosso alvo de pesquisa.

A metodologia por nós utilizada foi a da análise de conteúdo. Este enfoque metodológico permite um estudo detalhado do assunto, evidenciando o sentido das palavras e frases, e possibilita a rediscussão dos resultados. Elegemos três categorias para analisar as publicações: os focos dos trabalhos, sua abordagem em relação à formação inicial e/ou continuada de professores e a regionalização das instituições de pesquisa dos autores.

\section{Apresentação das revistas}

Conforme já indicado, buscamos analisar artigos relacionados à formação inicial e continuada de professores em duas revistas de circulação nacional: A Revista Brasileira de Educação e a Revista Zetetiké.

\section{Revista Brasileira de Educação - ANPEd}

A Associação Nacional de Pós-Graduação e Pesquisa em Educação (ANPEd) assume o papel de aglutinadora e representante dos programas de pós-graduação em educação. A associação de pesquisadores engajados e preocupados com a educação resultou em sua criação em 1978. Desde o seu início, organiza anualmente reuniões, com a finalidade de promover encontros e discussões acerca da Educação. Publica trimestralmente e distribui, por todo o território brasileiro, estudos sobre a educação. Sua divulgação on-line está disponibilizada no site SCielo, reconhecido mundialmente por publicar artigos científicos. Entre os anos de 2001 e 2010 foram publicados, ao todo, 313 artigos.

\section{Revista Zetetiké - FE - Unicamp}

A revista Zetetiké é organizada e publicada pela Faculdade de Educação da Universidade Estadual de Campinas (Unicamp). Seu foco de estudo é a Educação Matemática, área preferencial de pesquisa das autoras deste trabalho. A primeira revista, composta por quatro artigos, foi publicada em março de 1993, financiada pelo Fundo de Apoio ao Ensino e Pesquisa/Fundação de Desenvolvimento da Unicamp (Faep/ Unicamp). Sua divulgação atualmente se dá através da distribuição de exemplares para os assinantes e também pela Internet, no próprio site da Zetetiké. Até o final do ano de 2011 foram 
publicadas 35 edições, além de dois números temáticos: um em 2009, cujo tema foi o das Políticas Públicas; o outro, em 2010, que abordava as práticas sociais. Na primeira década do século XXI, foram publicados 105 artigos.

\section{Metodologia e apresentação dos artigos}

Para analisar os artigos que pesquisamos, foi necessário buscar caminhos metodológicos que nos auxiliassem. A partir de estudos realizados, indicamos que nossa pesquisa se enquadra no enfoque metodológico da análise de conteúdo. Fiorentini e Lorenzato (2006, p. 138) entendem-no como um estudo minucioso de conteúdo, das palavras e frases que dele fazem parte, buscando o sentido e captando as intenções, as divergências, avaliando e rejeitando os aspectos que não contribuem ou não são essenciais.

No que se refere ao recorte do período — artigos publicados entre os anos 2001 a 2010, primeira década do século XXI - justificamos essa escolha por interessar-nos o que vem sendo divulgado mais recentemente no âmbito da formação de professores. Nos periódicos, selecionamos artigos a partir dos descritores: concepção de formação inicial; formação profissional de docentes em início de carreira; formação continuada.

Uma primeira seleção dos artigos foi feita a partir da leitura de seus resumos. No caso da Revista Brasileira da Educação, inicialmente encontramos 23 artigos que nos interessaram. Após a leitura na íntegra de cada um deles, selecionamos, para a composição da pesquisa, nove que tratavam mais diretamente da formação inicial e/ou continuada de professores. Na revista Zetetiké, os quinze artigos, inicialmente selecionados a partir de seus resumos, tiveram sua leitura completa, pelo interesse de seu conteúdo para a nossa pesquisa. A seguir, apresentamos os 24 artigos que compõem o presente estudo.

\section{Artigos Da Revista Brasileira de Educação — ANPEd}

Buscamos primeiramente, na Revista Brasileira de Educação - ANPEd, os artigos envolvendo as palavras chave: concepção de formação inicial; formação profissional de docentes em início de carreira; formação continuada. Os nove artigos selecionados trazem diferentes abordagens acerca da formação inicial e continuada de professores. Em relação à procedência dos autores, há uma diversidade relacionada tanto à natureza das instituições — universidades públicas ou privadas - como no que se refere às suas regiões de atuação.

Quatro, dentre os nove artigos, foram escritos por autores que atuam em universidades públicas da região sudeste (EFES, UFMG, UERJ, USP, UFU, Unicamp); uma publicação tem por autor um pesquisador de universidade particular da região sudeste (PUC-Minas); um artigo foi escrito por dois autores: um da região sudeste e outro da região sul (USP e UFSC, ); outro produzido por dois pesquisadores, sendo um da região sudeste e o outro dos EUA (UFRRJ e ASU). Um oitavo artigo foi elaborado por uma pesquisadora da ANPEd; o nono adveio de pesquisa da Fundação Carlos Chagas. No que se refere às regiões de atuação dos autores, dez dentre os quinze pesquisadores atuam em universidades públicas e privadas da região sudeste (66\%, aproximadamente) e um na região sul. Os demais autores atuam junto à Universidade Americana, à ANPEd e à Fundação Carlos Chagas.

Quanto à abordagem — formação inicial e formação continuada —, cinco dentre os artigos relacionavam-se com a formação continuada, dois com a formação inicial e um deles com os dois focos de formação, tanto inicial como continuada. Quanto ao foco de estudo, três dentre os nove artigos abordavam a história da educação da pós-graduação no 
Brasil. Um dos artigos traz em seu foco principal as políticas públicas brasileiras de formação continuada. Um dos trabalhos traz um estudo relacionado ao uso da tecnologia da informação. Outro artigo refere-se a uma pesquisa que focava a formação e valorização do magistério a partir das vozes de profissionais da educação. Finalmente, e que para nós tem significado especial como já anteriormente indicado, encontramos, dentre os nove trabalhos relacionados à formação de professores na revista da ANPEd (anos de 2001 a 2010), dois com o foco de estudos na formação inicial de professores de matemática. No Quadro 1, as informações de que até aqui dispusemos sobre os artigos selecionados da Revista Brasileira de Educação.

QUADRO 1: ARTIGOS SELECIONADOS DA REVISTA BRASILEIRA DE EDUCAÇÃO

\begin{tabular}{|c|c|c|c|c|c|}
\hline $\mathrm{N}$ & Artigos & $\begin{array}{l}\text { Foco de } \\
\text { estudo }\end{array}$ & $\mathrm{FC}$ & $\mathrm{FI}$ & ANO \\
\hline 01 & $\begin{array}{l}\text { Os não-lugares dos professores nos entre-lugares de formação } \\
\text { continuada. } \\
\text { Janete M. Carvalho - Universidade Federal do Espírito Santo }\end{array}$ & $\begin{array}{l}\text { Formação } \\
\text { continuada }\end{array}$ & $x$ & & 2005 \\
\hline 02 & $\begin{array}{l}\text { O conhecimento matemático do professor: formação e prática docente } \\
\text { na escola básica. } \\
\text { Plínio Cavalcanti Moreira - Universidade Federal de Minas Gerais } \\
\text { Maria Manuela M. Soares David - Universidade Fed. Minas Gerais }\end{array}$ & $\begin{array}{l}\text { Formação de } \\
\text { prof. de } \\
\text { matemá-tica }\end{array}$ & & $x$ & 2005 \\
\hline 03 & $\begin{array}{l}40 \text { anos da pós-graduação em Educação no Brasil: produção do } \\
\text { conhecimento, poderes e práticas. } \\
\text { Betania Leite Ramalho - Presidente da ANPEd }\end{array}$ & $\begin{array}{l}\text { História da } \\
\text { Educação }\end{array}$ & $x$ & & 2006 \\
\hline 04 & $\begin{array}{l}\text { As tecnologias da informação e da comunicação na formação de } \\
\text { professores. } \\
\text { Raquel Goulart Barreto; Glaucia Campos Guimarães; Ligia Karam Corrêa } \\
\text { de Magalhãe; - Universidade Estadual do Rio de Janeiro } \\
\text { Elizabeth Menezes T. Leher - Universidade Federal do Rio de Janeiro }\end{array}$ & $\begin{array}{l}\text { Tec. da } \\
\text { inform. e } \\
\text { comunica- } \\
\text { ção }\end{array}$ & $x$ & $x$ & 2006 \\
\hline 05 & $\begin{array}{l}\text { Pós-graduação e pesquisa em Educação no Brasil: o protagonismo da } \\
\text { ANPEd. } \\
\text { Sandra Zákia Sousa - Universidade de São Paulo } \\
\text { Lúcidio Biacnchetti - Universidade Federal de Santa Catarina }\end{array}$ & $\begin{array}{l}\text { História da } \\
\text { Educação }\end{array}$ & $x$ & & 2007 \\
\hline 06 & $\begin{array}{l}\text { *Desafios e potencialidades da escrita na formação docente em } \\
\text { matemática. } \\
\text { Maria Teresa Menezes Freitas- Universidade Federal de Uberlândia. } \\
\text { Dario Fiorentini - Universidade Estadual de Campinas }\end{array}$ & $\begin{array}{l}\text { Formação de } \\
\text { profes. de } \\
\text { matemática }\end{array}$ & & $x$ & 2008 \\
\hline 07 & $\begin{array}{l}\text { Trinta por trinta: dimensões da pós-graduação em educação. } \\
\text { Carlos Roberto Jamil Cury - PUC - Minas Gerais }\end{array}$ & $\begin{array}{l}\text { História da } \\
\text { Educação }\end{array}$ & $x$ & & 2008 \\
\hline 08 & $\begin{array}{l}\text { Análise das políticas públicas para formação continuada no Brasil, na } \\
\text { última década. } \\
\text { Bernadete } A \text {. Gatti - Fundação Carlos Chagas }\end{array}$ & $\begin{array}{l}\text { Política } \\
\text { Pública }\end{array}$ & $x$ & & 2008 \\
\hline 09 & $\begin{array}{l}\text { Formação de professores e pedagogias críticas. É possível ir além das } \\
\text { narrativas redentoras? } \\
\text { Gustavo E. Fischan - Arizona State University } \\
\text { Sandra R. Sales - Universidade Fed. Rural do Rio de Janeiro }\end{array}$ & $\begin{array}{l}\text { Formação } \\
\text { continuada }\end{array}$ & $x$ & & 2010 \\
\hline
\end{tabular}

FC: formação continuada; FI: formação inicial ... Fonte: dados coletados pelas autoras

Como pudemos observar, entre os anos de 2001 a 2004 não encontramos artigos relacionados à formação de professores, seja inicial ou continuada, na revista da ANPEd. Por outro lado, a maior concentração de artigos se verifica no ano de 2008. Outra constatação é a de que a maior parte dos artigos foi escrita por autores que atuam em instituições da região sudeste brasileira. 


\section{Artigos da Revista Zetetiké - FE-Unicamp}

Desde as nossas primeiras buscas, a partir da leitura dos resumos dos artigos, foram encontrados quinze trabalhos na Revista Zetetiké envolvendo as palavras - chave: concepção de formação inicial, formação profissional de docentes em início de carreira e formação continuada. Os estudos apresentavam diferentes focos de estudo acerca da formação inicial e continuada de professores. Verificamos que os autores advêm de diferentes regiões e instituições públicas e privadas brasileiras e que um deles é de instituição portuguesa.

Dentre os quinze artigos escritos por trinta e dois autores, dois foram produzidos em instituições privadas brasileiras e dez em públicas; dois, em universidades portuguesas e um dos artigos foi escrito por três autores, dois deles de universidade estadual e um de universidade particular brasileira. Em relação ao local de atuação dos 32 autores, ou seja, suas universidades de origem, 23 trabalham na região sudeste e cinco na região sul do Brasil; os quatro restantes atuam em Portugal. Quanto à abordagem dos artigos sobre formação inicial de professores e formação continuada, verificamos que, dentre os quinze artigos, dez têm como foco a formação inicial e cinco a formação continuada de professores.

No que se refere ao foco de estudo, quatro dentre os quinze artigos abordam a didática do professor em relação à sua formação inicial; quatro apresentam aspectos sobre a importância do currículo para a formação inicial de professores em Educação Matemática; dois, que trazem contribuições sobre a formação continuada de professores, têm como foco de estudo as Políticas Públicas; um refere-se a uma pesquisa que estudou a interdisciplinaridade para a formação continuada de professores e as contribuições possíveis ao articular outros conteúdos de diferentes áreas do conhecimento para ensinar matemática; um traz estudos sobre as contribuições dos recursos de um laboratório de materiais pedagógicos para a formação inicial de professores de matemática. Em relação à formação inicial de professores, um estudo tem como centro as tecnologias da informação e comunicação no ensino de matemática, um mais coloca sua abordagem principal na Avaliação. Um último artigo traz como foco de estudo a revisão bibliográfica de quinze anos de publicação dos artigos da Revista Zetetiké sobre a formação continuada de professores, entre os anos de 1993 a 2007. No Quadro 2, trazemos o resumo das informações anteriormente descritas.

QUADRO 2: ARTIGOS SELECIONADOS DA REVISTA ZETETIKÉ - FE/UNICAMP

\begin{tabular}{|c|c|c|c|c|c|}
\hline $\mathrm{N}^{\circ}$ & Artigos & $\begin{array}{l}\text { Foco de } \\
\text { estudo }\end{array}$ & FC & $\mathrm{FI}$ & Ano \\
\hline 01 & $\begin{array}{l}\text { Educação Matemática e Ambiental: uma proposta de formação } \\
\text { continuada - e de mudanças. } \\
\text { Ademir Donizete Caldeira - Universidade de Uberaba } \\
\text { João F. da Costa A. Meyer - Universidade Estadual de Campinas }\end{array}$ & $\begin{array}{l}\text { Interdiscipl } \\
\text { inaridade }\end{array}$ & $x$ & & 2001 \\
\hline 02 & $\begin{array}{l}\text { Os graduandos em Pedagogia e suas filosofias pessoais frente à } \\
\text { matemática e seu ensino } \\
\text { Adair Mendes Nacarato - Universidade Estadual de Campinas } \\
\text { Cármen Lúcia B. Passos - Universidade Federal São Carlos } \\
\text { Dione L. de Carvalho - Universidade Estadual de Campinas }\end{array}$ & Didática & & $x$ & 2004 \\
\hline 03 & $\begin{array}{l}\text { Por que análise real na licenciatura? } \\
\text { Plínio C. Moreira - Universidade Federal de Minas Gerais } \\
\text { Helena Noronha Cury - PUC-Rio Grande do Sul } \\
\text { Carlos Roberto Vianna - Universidade do Paraná }\end{array}$ & Currículo & & $x$ & 2005 \\
\hline
\end{tabular}




\begin{tabular}{|c|c|c|c|c|c|}
\hline 04 & $\begin{array}{l}\text { Aprender matemática investigando } \\
\text { Alexandro Rocha e João Pedro da Ponte - Universidade de Lisboa }\end{array}$ & Didática & & $x$ & 2006 \\
\hline 05 & $\begin{array}{l}\text { O Laboratório de Ensino Matemática: implicações na formação de } \\
\text { professores } \\
\text { Jairo de Araújo Lopes e Elizabeth A. de Araújo PUC-Campinas }\end{array}$ & $\begin{array}{l}\text { Recursos } \\
\text { Materiais }\end{array}$ & & $x$ & 2007 \\
\hline 06 & $\begin{array}{l}\text { Modelagem Matemática na escola e na formação do professor } \\
\text { Samuel Jurkiewicz - Universidade Federal do Rio de Janeiro } \\
\text { Clícia Valladores P. Fridermann - Univ. Fed. Rio de Janeiro }\end{array}$ & Currículo & & $x$ & 2007 \\
\hline 07 & $\begin{array}{l}\text { Uma análise interpretativa da produção escrita em matemática de } \\
\text { alunos da escola básica } \\
\text { João Ricardo V. dos Santos- Universidade Estadual de São Paulo } \\
\text { Regina Luzia C. de Buriasco- Universidade Estadual de Londrina }\end{array}$ & Avaliação & $x$ & & 2008 \\
\hline 08 & $\begin{array}{l}\text { Políticas públicas: diferentes interfaces sobre a formação do professor } \\
\text { de Matemática } \\
\text { Rosana de Oliveira - Universidade Estadual do Rio de Janeiro }\end{array}$ & $\begin{array}{l}\text { Políticas } \\
\text { Públicas }\end{array}$ & & $x$ & 2009 \\
\hline 09 & $\begin{array}{l}\text { Vivências de professores de matemática em início de carreira na } \\
\text { utilização da informação e comunicação } \\
\text { Reginaldo F. Carneiro - Universidade Federal de São Carlos } \\
\text { Cármen Lúcia B. Passos- Universidade Federal de São Carlos }\end{array}$ & $\begin{array}{l}\text { Tec. da } \\
\text { inform. e } \\
\text { comunicaç } \\
\text { ão }\end{array}$ & & $x$ & 2009 \\
\hline 10 & $\begin{array}{l}\text { Formação profissional de professores de matemática em serviço e } \\
\text { políticas públicas } \\
\text { Maria Elidia Teixeira Reis- Universidade Estadual de Campinas } \\
\text { Dario Fiorentini - Universidade Estadual de Campinas }\end{array}$ & $\begin{array}{l}\text { Políticas } \\
\text { Públicas }\end{array}$ & & $x$ & 2009 \\
\hline 11 & $\begin{array}{l}\text { Grupo colaborativo e desenvolvimento profissional de formadores de } \\
\text { professores de matemática } \\
\text { Armando Traldi Júnior - PUC - São Paulo } \\
\text { Célia Maria Carolino Pires - PUC - São Paulo }\end{array}$ & Currículo & & $x$ & 2009 \\
\hline 12 & $\begin{array}{l}\text { Os sentidos sobre o professor e sua formação em } 15 \text { anos de zetetiké: } \\
1993 \text { - } 2007 \\
\text { Marinez Maneghello Passos - Universidade Estadual de Londrina } \\
\text { Roberto Nardi - Universidade Estadual de São Paulo } \\
\text { Sérgio de Mello Arruda - Universidade Estadual de Londrina }\end{array}$ & $\begin{array}{l}\text { Revisão } \\
\text { Bibliográfi } \\
\text { ca }\end{array}$ & $x$ & & 2010 \\
\hline 13 & $\begin{array}{l}\text { Curso de Pedagogia e de Matemática formando professores de } \\
\text { Matemática para os anos iniciais do Ensino Fundamental: em busca de } \\
\text { uma compreensão } \\
\text { Ana Paula P. Baumann e Maria Ap. Viggiani Bicudo Universidade } \\
\text { Estadual de São Paulo }\end{array}$ & Currículo & & $x$ & 2010 \\
\hline 14 & $\begin{array}{l}\text { A comunicação promovida por futuros professores na aula de } \\
\text { Matemática } \\
\text { Matilde Gonçalves Almeida - Universidade do Minho - Portugal } \\
\text { José Antônio Fernandes- Universidade do Minho - Portugal }\end{array}$ & Didática & & $x$ & 2010 \\
\hline 15 & $\begin{array}{l}\text { O sentido em movimento na formação de professores de Matemática } \\
\text { Vanessa Dias Moretti - Universidade Federal de São Paulo } \\
\text { Manoel Orisvaldo de Moura - Universidade de São Paulo }\end{array}$ & Didática & & $x$ & 2010 \\
\hline
\end{tabular}

FC: formação continuada; FI: formação inicial ... Fonte: dados coletados pelas autoras

Como observado nas informações do Quadro 2, os autores dos artigos publicados na revista Zetetiké, em sua maioria (72,5\%), atuam na região sudeste brasileira, a exemplo do que encontramos na Revista Brasileira de Educação - ANPEd. Cinco outros autores (15\%) são de universidades da região sul do Brasil e quatro autores (12,5 \%) são de universidades portuguesas. Não encontramos nenhum trabalho relacionado à formação de professores, inicial ou continuada, publicado na primeira década do século XXI na Revista Zetetiké escrito por autores que atuassem nas regiões centro-oeste, nordeste ou norte do Brasil. 


\section{Propostas de análises: entrelaçamento das informações apresentadas nos artigos das duas revistas}

Iniciamos nossa análise, verificando a distribuição dos artigos que abordavam a formação inicial e/ou continuada de professores, ao longo do período de 2001 a 2010.

Nos quatro primeiros anos, entre 2001 e 2004, analisando os dois periódicos, encontramos apenas um artigo publicado na Revista Zetetiké, em 2001, que trata da interdisciplinaridade, e está relacionado à formação continuada de professores em início de carreira. Somando-se esse artigo aos demais 23, publicados entre os anos de 2005 e 2010, verificamos que configuram um total de menos de $6 \%$ dos artigos publicados sobre esse assunto em ambas as revistas. Nosso estranhamento em relação a esse fato se dá em função de que há pesquisas sendo realizadas em maior número acerca da formação de professores, desde a segunda metade do século XX, e de que, por isso, pudessem ter sido mais amplamente encontradas nesses periódicos, que se dedicam à divulgação de pesquisas sobre a área da Educação. Afinal, para Nacarato et al. (2009, p. 9) "Há muito a dizer e narrar sobre práticas da sala de aula e sobre a formação das profissionais que atuam nesse nível de ensino" no início de suas carreiras. No entanto, embora as pesquisas estejam de certa maneira sendo numericamente ampliadas, ainda há pouca divulgação delas.

Selecionamos os artigos, de acordo com seus objetivos de estudos, em categorias, aglutinando focos comuns. Elegemos três eixos de análise: Focos específicos das publicações e o periódico em que foram divulgados; Formação inicial e formação continuada; A regionalização dos autores.

Primeiro eixo: Focos específicos das publicações e o periódico em que foram divulgados

Analisando os artigos publicados nas duas revistas, podemos perceber que aqueles encontrados na Revista Brasileira de Educação abordam diferentes focos de estudo sobre formação inicial e/ou continuada de professores: formação continuada, formação de professores de matemática, história da Educação, tecnologia da informação e comunicação e políticas públicas. Já os que encontramos na Zetetiké têm como temas de estudo a interdisciplinaridade, didática, currículo, recursos materiais, avaliação, políticas públicas, tecnologia da informação e comunicação e revisão bibliográfica.

Como pudemos constatar no que se refere à formação inicial e/ou continuada de professores, encontramos dois focos comuns aos dois periódicos: o uso de Tecnologias de Informação e Comunicação (TIC) e as Políticas Públicas de formação de professores. A seguir traremos nossas análises acerca desses dois focos.

Sobre o uso de tecnologias, na análise da Revista Brasileira de Educação e da Revista Zetetiké, encontramos, em cada uma delas, um artigo em que o uso das tecnologias era abordado. Na Revista Brasileira de Educação, o estudo foi publicado em 2005 e traz parte do resultado de uma pesquisa de estado do conhecimento, produzida a partir de 186 dos 331 documentos — teses, dissertações e artigos —, publicados entre 1996 e 2002, cujos autores fizeram diagnóstico e análise sobre publicações que destacaram a contribuição das tecnologias para a formação inicial e continuada de professores.

Na Revista Zetetiké, o artigo referente a esse foco foi publicado em 2009, e traz aspectos do uso da tecnologia, principalmente no início de carreira docente, já que, segundo os autores, este recurso auxilia o docente em suas primeiras experiências dentro 
de sala de aula. Destacam que, além das dificuldades de manter a disciplina, motivar os alunos, cumprir programas, a utilização das (TIC) também traz desafios.

[...] a organização em duas turmas para usar o computador, o ritmo mais lento das aulas com as tecnologias devido à sua dinâmica, a falta de conhecimento das ferramentas tecnológicas pelos alunos, a imprevisibilidade e a improvisação, a opção por aulas com esse recurso para cumprir todo o programa, entre outras (CARNEIRO; PASSOS, 2009, p. 130).

Nos dois textos foi possível verificar a necessidade de que as TIC sejam utilizadas na formação inicial e continuada de professores. O que se faz importante destacar é a qualidade do uso desse recurso, tanto no que diz respeito aos cursos de formação, quanto às ferramentas disponíveis para o professor na sua atuação docente. Quanto ao foco das políticas públicas, comum nas duas revistas, identificamos um artigo na Revista Brasileira de Educação e dois na Revista Zetetiké.

O artigo da Revista Brasileira de Educação foi publicado em 2008. Trata-se de um estudo que analisa historicamente como a educação continuada no Brasil se desenvolve. Para sua autora, a educação continuada tem se constituído muito mais como um suprimento em relação ao déficit na formação de professores no nível da graduação do que "de aprofundamento ou ampliação de conhecimentos. Isso responde a uma situação particular nossa, pela precariedade em que se encontram os cursos de formação em nível de graduação" (GATTI, 2008, p. 58). A autora ainda complementa indicando que:

Muitas iniciativas públicas de formação continuada no setor educacional adquiriram, então, a feição de programas compensatórios e não propriamente de atualização e aprofundamento em avanços do conhecimento, sendo realizados com a finalidade de suprir aspectos da má-formação anterior, alterando o propósito inicial essa educação [...] (GATTI, 2008 p. 58).

O estudo também aponta as preocupações em relação aos programas e aos projetos e aos inúmeros cursos de especialização sem a qualidade e critérios adequados. A autora finaliza questionando que o investimento público seria mais adequado na ampliação de vagas para formação de professores em instituições públicas.

Na Revista Zetetiké, foram publicados dois artigos relacionados às políticas públicas, ambos no ano de 2009. O primeiro deles - "Políticas Públicas: diferentes interfaces sobre a formação do professor de Matemática" - (OLIVEIRA, 2009), analisa como o papel do Estado se articula e se reflete nas políticas públicas de formação de professores de Matemática. A autora analisa criticamente os Parâmetros Curriculares Nacionais (PCN) de Matemática (1997), documentos elaborados pelo Ministério da Educação (MEC), justificando que sua análise traz argumentos para a compreensão dos mecanismos que estão por trás das ações que configuram as políticas públicas, sobretudo no que se refere à educação matemática. Segundo a autora, existem muitos fatores que possibilitam atingir a qualidade educacional, que não somente uma ação política. Ela complementa que há a necessidade de participação de todos que estão inseridos no ambiente educacional.

[...] Acredito que professores e alunos são participantes importantes desse processo. Não no sentido de inverter e colocar o professor como o grande "vilão" ou "salvador da prática" e o aluno como grande "vítima" do processo. Entendo que os discursos dos documentos e as práticas discursivas que circulam no interior da escola, a mídia e as pesquisas 
acadêmicas se relacionam por processos híbridos para constituir o que temos. Portanto, as ações políticas que envolvem o campo da Educação não acontecem numa direção única (OLIVEIRA, 2009, p. 32).

O outro artigo aborda a formação profissional de professores de matemática em serviço e políticas públicas. O estudo analisa um curso emergencial de Licenciatura Plena Parcelada em Matemática, no estado de Goiás, o qual foi criado a partir de uma parceira entre a Universidade Estadual de Goiás e a Secretaria de Estado de Educação, para regulamentar a LDB n 9.394/96. O curso teve como objetivo a capacitação em nível superior dos docentes em Educação Básica. Embora as intenções definidas no projeto representassem uma positiva intenção de habilitar os professores em licenciatura plena específica, o intento não foi alcançado. Segundo os autores, o principal fator foi em relação às políticas públicas que "não levaram em consideração a complexidade do trabalho docente dos professores-alunos em diferentes contextos de prática" (REIS; FIORENTINI, 2009, p. 146). Outro fator diz respeito às práticas didático-pedagógicas privilegiadas pelo curso que tomou por base as "experiências e saberes que os professores construíram e desenvolveram ao longo de seus anos de docência" (Ibidem, p. 147).

Nos três artigos relacionados às políticas públicas, podemos verificar que ações políticas são fundamentais para o desenvolvimento educacional. Fica evidenciada em cada um dos artigos a importância da necessidade de investir, sobretudo na melhoria dos cursos de licenciatura no nível da graduação, ou seja, na formação inicial dos professores. As leis vigentes, os documentos e as diretrizes trazem, na teoria, como seria uma educação de qualidade, o que nem sempre ocorre na prática. Ainda podemos depreender da análise feita nos artigos que organizar leis e projetos não é o suficiente para assegurar a qualidade da educação escolar básica. Mais que isso, é necessário acompanhar como a implementação das leis e projetos acontecem, verificando a sua viabilização e eficácia. Reis e Fiorentini (2009, p.124) apresentam uma concepção que de certa maneira foi encontrada em cada um desses artigos relacionados às políticas públicas, qual seja:

Discutir a formação dos professores tem sido uma preocupação crescente entre estudiosos do campo da educação, pois, nos últimos anos, as concepções de formação vêm sendo questionadas e modificadas, principalmente, por seu descompasso em relação aos desafios e às mudanças sociais, políticas, econômicas, culturais e tecnológicas da sociedade atual.

\section{Segundo eixo: Formação inicial e formação continuada}

Julgamos importante configurar um quadro com informações necessárias para o aprofundamento das leituras dos artigos. Conforme descrito, o foco de estudo foi um dos itens essenciais para a classificação deles. Outro aspecto inserido no quadro para a análise foi identificar, nos artigos previamente selecionados, a existência das palavras-chave: formação inicial e/ou formação continuada de professores.

Dentre os vinte e quatro artigos selecionados no período de 2001 a 2010, treze focavam apenas a formação inicial de professores (dois na Revista Brasileira de Educação e onze na Zetetiké); dez artigos abordavam estudos relacionados à formação continuada de professores (seis na Revista Brasileira de Educação e quatro na Zetetiké); apenas um artigo publicado na Revista Brasileira de Educação aprofundava-se sobre a formação inicial e continuada de professores concomitantemente. 
Os dados que constituíram o quadro anterior permitem-nos visualizar, no Gráfico 1, a distribuição de publicação dos artigos no período por nós estabelecido:

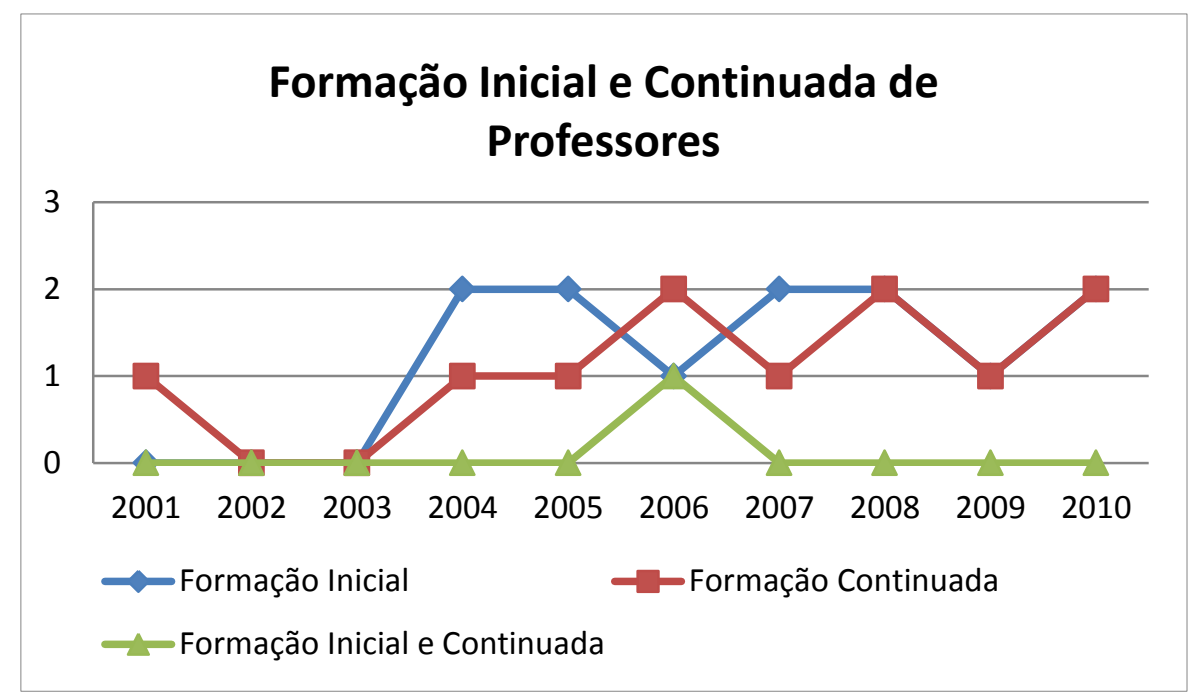

GRÁFICO 1: Distribuição da publicação dos artigos referentes à pesquisa ... Fonte: dados coletados pelas autoras

A partir do gráfico apresentado e das análises realizadas sobre as publicações, entendemos que a Revista Zetetiké concentra um maior número percentual de publicações sobre formação Inicial e continuada de professores, uma vez que, no período por nós estudado, encontramos 15 dentre os 105 artigos publicados relacionados a esse tema, ou seja, 14,28\% das publicações. Já a Revista Brasileira de Educação tem apenas 2,87\% de seus artigos publicados com a temática da formação de professores, ou seja, nove dentre as 313 publicações.

\section{Terceiro Eixo: A regionalização dos autores}

Ao analisar os artigos verificamos a procedência dos autores no que se refere às suas instituições de origem. Constatamos uma maior concentração dos pesquisadores nas regiões sudeste e sul. Na Revista Brasileira de Educação, não foi encontrado nenhum artigo sobre formação de professores advindo de pesquisadores das regiões norte, nordeste e centro-oeste. Entre os dezesseis autores dos artigos, foram identificados doze da região sudeste (75\%), um da região sul (6,2\%), dois autores estão ligados às instituições em nível nacional (12,5\%, sendo um da ANPEd e outro da Fundação Carlos Chagas; e um autor (6,2\%) é pesquisador de Universidade dos Estados Unidos. No Gráfico 2 será possível visualizar a distribuição geográfica das publicações na Revista Brasileira de Educação (RBE): 


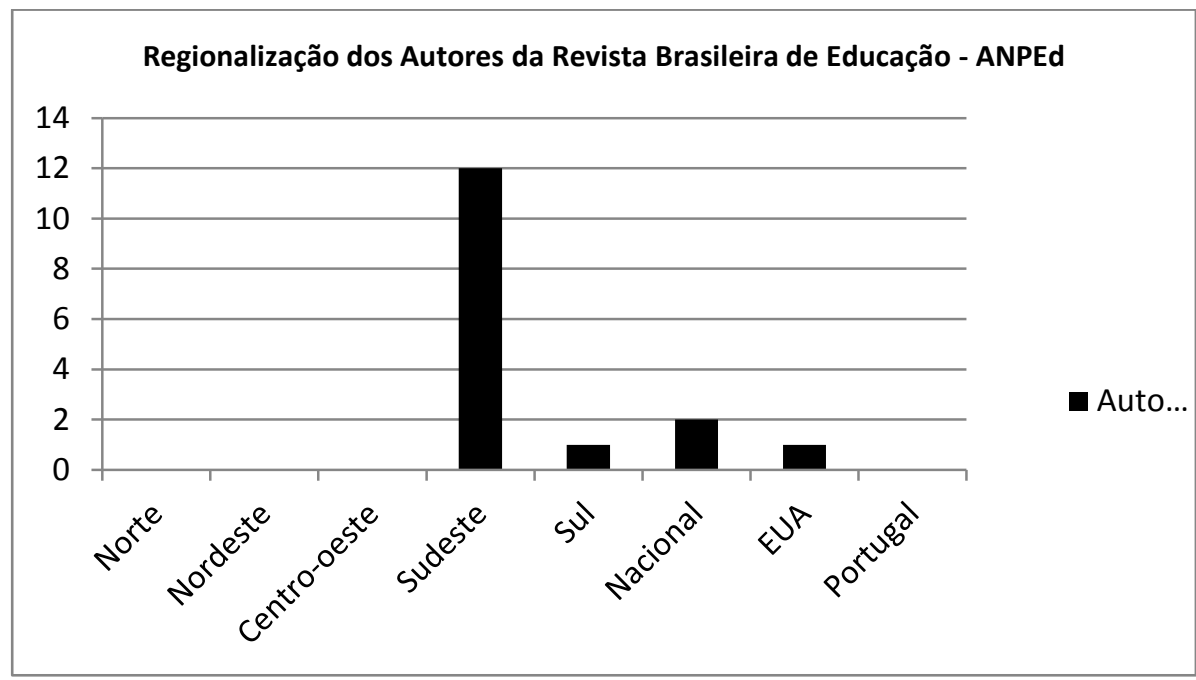

GRÁFICO 2: Regionalização dos autores de trabalhos sobre formação de professores na Revista Brasileira de Educação ... Fonte: dados coletados pelas autoras

Na Revista Zetetiké, a distribuição não difere muito. Dentre os 32 autores, não encontramos nenhum pesquisador com procedência das regiões norte, nordeste e centrooeste. De maneira assemelhada à outra revista, a concentração está na região sudeste com 23 autores (71,8\%); cinco outros autores advêm de instituições da região sul (15,6\%) e quatro outros autores são procedentes de instituições portuguesas (12,5\%).

No Gráfico 3, a distribuição por regiões dos autores de trabalhos sobre formação de professores publicados na Zetetiké:



Gráfico 3: Regionalização dos autores de trabalhos sobre formação de professores na Revista Zetetiké ... Fonte: dados coletados pelas autoras

O fato de as revistas pesquisadas serem diretamente relacionadas à educação e de terem como semelhança a concentração dos autores-pesquisadores de suas publicações das regiões sul e sudeste, permite-nos uma indagação: as pesquisas nas demais regiões são feitas em menor número ou são menos divulgadas? A resposta merece discussão pelos pesquisadores da área da educação e também dos editores das revistas. 


\section{Considerações finais}

A partir das análises feitas nos dois periódicos é possível traçar algumas considerações relacionadas a como as pesquisas sobre a formação inicial e/ou continuada vêm sendo difundidas nesses veículos de difusão do conhecimento científico. Retomamos que menos de $6 \%$ dos artigos publicados na Revista Brasileira de Educação e na Zetetiké abordam essas temáticas. Vale destacar que esta última traz, mais especificamente, resultados de pesquisas direcionadas ao ensino e à aprendizagem de matemática, por ter uma maior concentração dessa temática.

Reforçamos ainda a evidente concentração de publicações de artigos escritos por pesquisadores das regiões sudeste e sul do Brasil. Esta é uma preocupação que se direciona em dois sentidos: o primeiro se refere à produção de pesquisas relacionadas à formação de professores como ainda tímida nas demais regiões do país; segundo, se, no geral, as publicações das mesmas revistas têm ou não trazido artigos advindos de espaços de pesquisa das regiões norte, nordeste e centro-oeste do Brasil.

Com o aumento de Programas de Pós Graduação nas regiões norte e nordeste do Brasil, nos últimos anos, é provável que o desenvolvimento de pesquisas na área de educação se estabeleça nesses espaços e ocorra a consequente divulgação das mesmas.

Na nossa compreensão, há ainda muito que entender, estudar e pesquisar, em todos os espaços onde a educação se faz presente no nosso país, na perspectiva de identificação de ações que possibilitem a implementação de um ensino de qualidade direcionado às diferentes etapas de ensino no Brasil.

\section{Referências}

ALMEIDA, M.; FERNANDES, J. A. A comunicação promovida por futuros professores na aula de Matemática. Zetetiké- Faculdade de Educação- Unicamp, SP, v18. , n. 34, 2010.

BARRETO, R. et al. As tecnologias da informação e da comunicação na formação de professores. Revista Brasileira de Educação - ANPEd, Rio de Janeiro, v. 11, n. 31, 2006.

BAUMANN, A. P. P.; BICUDO, M. A. V. Cursos de Pedagogia e de Matemática formando professores de Matemática para os anos iniciais do Ensino Fundamental: em busca de uma compreensão. Zetetiké- Faculdade de Educação- Unicamp, SP, v. 18, n. 34, 2010.

CALDEIRA, A. D.; MEYER, J. F. C. A. Educação matemática e ambiental: uma proposta de formação continuada - e de mudanças. Zetetiké - Faculdade de Educação, Unicamp, SP, v. 9, n. 15/16, 2001.

CARNEIRO, R. F.; PASSOS, C. L. B. Vivências de professores de matemática em início de carreira na utilização da informação e comunicação. Zetetiké- Faculdade de Educação- Unicamp, SP, v. 17, n. 32, p. 130, 2009.

CARVALHO, J.M. Os não-lugares dos professores nos entre lugares de formação continuada. Revista Brasileira de Educação - ANPEd, Rio de Janeiro, v. 12, n. 28, 2005.

CURY, C. R. J. Trinta por trinta: dimensões da pós-graduação em educação. Revista Brasileira de Educação - ANPEd, Rio de Janeiro, v. 13, n. 37, 2008.

FICHMAN, G.E.;SALES, S.R. Formação de professores e pedagogias críticas. É possível ir além das narrativas redentoras? Revista Brasileira de Educação - ANPEd, Rio de Janeiro, v. 15, n. 43, 2010

FIORENTINI, D.; LORENZATO, S. A. Investigação em educação matemática: percursos teóricos e metodológicos. Campinas, SP: Autores Associados, 2006. p.138. 
FREITAS, M. T. M.; FIORENTINI, D. Desafios e potencialidades da escrita na formação docente em matemática. Revista Brasileira de Educação - ANPEd, v. 13, n. 37, 2008.

GATTI, B. A. Análise das políticas públicas para formação continuada no Brasil, na última década. Revista Brasileira de Educação - ANPEd, Rio de Janeiro, v. 13, n. 37, 2008

JURKIEWICZ, S.; FRIDERMANN, C. V. P. Modelagem Matemática na escola e na formação dos professores. Zetetiké- Faculdade de Educação, Unicamp, SP, v. 15, n. 28, 2007.

LOPES, J. A.; ARAÚJO, E. A. O laboratório de ensino de Matemática: implicações na formação de professores. Zetetiké — Faculdade de Educação- Unicamp, SP, v. 15, n. 27, 2007.

MOREIRA, P. C.; DAVID, M. M. M. S. O conhecimento matemático do professor: formação e prática docente na escola básica. Revista Brasileira de Educação - ANPEd, Rio de Janeiro, v.12, n. 28, 2005

MOREIRA, P. C.; CURY, H. N.; VIANNA, C. R. Por que análise real na licenciatura? Zetetiké- Faculdade de Educação, Unicamp, SP, v. 13, n. 23, 2005.

MORETTI, V. D.; MOURA, M. O sentido na formação de professores de matemática. Zetetiké Faculdade de Educação- Unicamp, SP, v.18, n 34., 2010.

NACARATO, A. M.; PASSOS, L. B.. ; CARVALHO, D. L. Os graduandos em Pedagogia e suas filosofias pessoais frente à matemática e seu ensino. Zetetiké - Faculdade de Educação- Unicamp, SP, v.12, n. 21, 2004.

OLIVEIRA, R. Políticas Públicas: diferentes interfaces sobre a formação do Professor de Matemática. Revista Zetetiké (Revista Temática), Faculdade de Educação- Unicamp, SP v.17, p. 32, 2009.

PASSOS, M. M.; NARDI, R.; ARRUDA, S. M. Os sentidos sobre o professor e sua formação em 15 anos de Zetetiké: 1993- 2007. Zetetiké- Faculdade de Educação- Unicamp, SP, v. 18, n. 34, 2010.

RAMALHO, B. L. 40 anos da pós-graduação em Educação no Brasil: produção do conhecimento, poderes e práticas. Revista Brasileira de Educação - ANPEd, Rio de Janeiro, v. 11, n. 31, 2006.

REIS, M. E. T.; FIORENTINI, D. Formação profissional de professores de matemática em serviço e políticas públicas. Zetetiké - Faculdade de Educação, Unicamp, SP, v. 17, p. 124-146-147, 2009.

ROCHA, A.; PONTE, J. P. Aprender matemática investigando. Zetetiké - Faculdade de Educação, Unicamp, SP, v. 14, n. 26, 2006.

SANTOS, J. R. V.; BURIASCO, R. L. C. Uma análise interpretativa da produção escrita em matemática de alunos da escola básica. Zetetiké- Faculdade de Educação, Unicamp, SP, v. 16, n. 30, 2008.

SOUSA, S. Z.; BIANCHETTI, L. Pós-graduação e pesquisa em Educação no Brasil: o protagonismo da ANPEd. Revista Brasileira de Educação - ANPEd, Rio de Janeiro, v. 12, n. 36, 2007.

TRALDI JÚNIOR, A.; PIRES, C. M. C. Grupo colaborativo e o desenvolvimento profissional de formadores de professores de matemática. Zetetiké- Faculdade de Educação, Unicamp, SP. v. 17, n. $31,2009$. 